\title{
АНАЛІЗ ПРОБЛЕМ СТВОРЕННЯ ТЕХНОЛОГІЧНИХ РОБОТІВ ВЕРТИКАЛЬНОГО ПЕРЕММЩЕННЯ
}

\author{
Анотація: розглядаються проблеми створення технологічних роботів вер- \\ тикального переміщення, а саме способи приведення їх у рух, способи закрі- \\ плення на поверхнях і метод розрахунку умов утримання робота на поверхні. \\ Ключові слова: мобільні роботи, роботи вертикального переміщення.
}

\section{Вступ}

Технологічні роботи вертикального переміщення е різновидом мобільних роботів і як об'єкт дослідження представляють широкий інтерес в світовій робототехніці. Головною особливістю керування даним класом роботів $є$ необхідність враховувати гравітаційну складову в сукупності динамічних навантажень

Останні кілька років у розвинених країнах світу ведуться інтенсивні дослідження, спрямовані на створення мобільних дистанційно-керованих роботів, які можуть переміщатися по горизонтальних, похилих або вертикальних поверхнях. Такі роботи мають бути здатні долати перешкоди, що зустрічаються на їх шлях, повертатись в початкову точку, виконувати необхідні технологічні операції. Необхідність створення таких роботів і робототехнічних комплексів обумовлюеться виникаючими екстремальними ситуаціями, збільшеними вимогами виконання технологічних операцій і умовами, в яких людині небезпечно перебувати або складно виконувати дії самому. Основними проблемами розробки технологічних роботів вертикального переміщення (ТР ВП) є вибір способу закріплення робота на поверхні, вибір способу переміщення та розрахунок параметрів конструкції і необхідних сил для утримання і руху. Кожна з цих проблем $е$ досить широкою $\mathrm{i}$ має свій спектр можливих підходів до їх вирішення, при цьому кожний спосіб руху чи прикріплення до поверхні та різні методики розрахунку параметрів мають як свої переваги так і недоліки.

\section{Загальна схема ТP ВП}

Загальна схема ТР ВП, що наведена на рис. 1 включае в себе систему приводів (СП), систему керування (CК), блок перетворювачів (БП), датчики зворотного зв'язку (ДЗЗ), блок живлення (БЖ). Система управління представляе собою спеціалізований мікроконтролер чи ЕОМ. Інформація про об'єкт маніпулювання чи про навколишне оточення передається с датчиків Д.

У загальному випадку, при використанні в структурі робота системи пневмоприводів, в блоці электропневмоперетворювачів БП,

(c) В.К. Персиков, М.М. Поліщук, 2014 


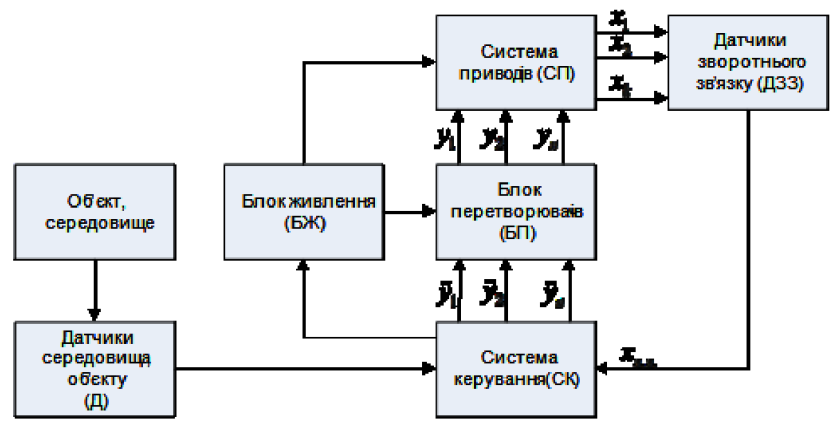

Рис. 1 - Загальна структура ТР ВП

що представляє собою, в такому випадку, пневматичні клапани з електричним керуванням, електричні сигнали керування приводами $\tilde{y}_{1}, \tilde{y}_{2}, \ldots, \tilde{y}_{n}$ перетворюються у відповідні сигнали тиску повітря $y_{1}, y_{2}, \ldots, y_{n}$, що надходить в робочий об'єм пневмоциліндрів. За допомогою датчиків ДЗЗ, в ланцюзі зворотного зв'язку вимірюються параметри $x_{1}, x_{2}, \ldots, x_{k}$ захватних пристроїв і виконавчих механізмів. Це необхідно для відстеження сигналів, що сигналізують, наприклад, про кінець виконання робочої операції або про гранично допустимі ступені вакууму в захватних пристроях. Крім того, частина датчиків встановлюється на технологічному обладнанні з метою перетворення і передачі інформації про виконання функціональних операцій роботом, наприклад, контрольновимірювальної інформації про якість досліджуваної поверхні, про результати дефектоскопії зварних швів, про закінчення та якість виконання фрарбувальних робіт і т. п. Блок живлення БЖ забезпечує живлення комплексу в цілому.

\section{Розрахунок умов фіксації робота на поверхні}

Для роботи ТР ВП на поверхні необхідно провести розрахунок параметрів для виконання умов рівноваги робота. Це необхідно для фріксації робота на вертикальній чи нахиленій поверхні. Розглянемо ТР ВП найпростішої конструкції, спрощена схема якого представлена на рис. 2. Робот складається з корпусу і маніпуляторів з захватними пристроями. Важливим завданням механіки, рішення якого забезпечує надійне функціонування робота, є визначення умов, що гарантують надійний контакт маніпуляторів 3 поверхнею при заданих зовнішніх силах, що накладені на робота. Далі розглянемо один з можливих підходів до вирішення цієї задачі і зробимо розрахунок тих зусиль, при яких робот утримуеться на поверхні без проковзування.

Пов'яжемо Декартову систему координат $O_{x y z}$ з нерухомою планарною поверхнею, по якій робот здійснює переміщення. Площину 


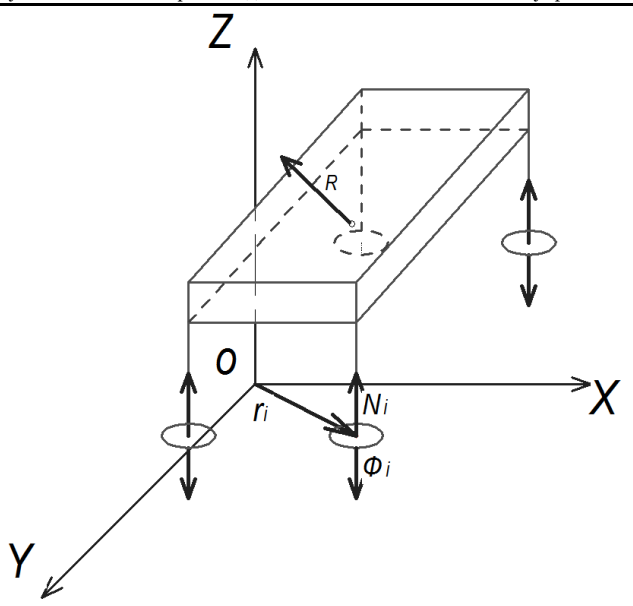

Рис. 2 - Спрощена модель ТР ВП

$O_{x y}$ сполучимо з поверхнею, а ось $z$ направимо в сторону, де знаходиться робот (рис. 2). Через $r_{i}$ зазначимо радіус-вектори центрів стоп, $i=1 . . n$. На робота в стані рівноваги діють наступні сили:

1) Зовнішні активні сили; головний вектор цих сил позначимо через $R$, а їх головний момент відносно точки $\mathrm{O}$ - через $M_{O}$.

2) Нормальні реакції поверхні; силу реакції, прикладену до і-тої стопи, позначимо через $N_{i} k$, де $\mathrm{k}$ - орт осі $z$, а $N_{i}>0, i=1 . . n$.

3) Дотичні реакції поверхні (сили сухого тертя); силу тертя діючу на і-ту стопу, позначимо через $F_{i}, i=1 . . k$. Сили тертя знаходяться в площині $O_{x y}$ і задовольняють закон сухого тертя Кулона

$$
\left|F_{i}\right| \leqslant f N_{i},
$$

де $f$ - коефіціент тертя.

4) Сили $\Phi_{i} k, i=1 . . n$, з якими стопи притискаються до поверхні, за рахунок наявності вакууму:

$$
\Phi_{i}=\left(P-P_{i}\right) S_{i}>0, i=1 . . n,
$$

де $P$ - атмосферний тиск, $P_{i}$ - тиск у і-му захваті; $S_{i}$ - площа захвата. Запишемо умови рівноваги робота під дією прикладених сил:

$$
\begin{gathered}
R+\sum\left[\left(N_{i}-\Phi_{i}\right) k+F_{i}\right]=0, \\
M_{O}+\sum r_{i} \times\left[\left(N_{i}-\Phi_{i}\right) k+F_{i}\right]=0
\end{gathered}
$$

Спроектуемо їх на осі координат. Таким чином отримуемо наступні дві групи рівнянь: 


$$
\begin{gathered}
R_{x}+\sum X_{i}=0, R_{y}+\sum Y_{i}=0, R_{z}+\sum\left(N_{i}-\Phi_{i}\right)=0 ; \\
M_{x}+\sum y_{i}\left(N_{i}-\Phi_{i}\right)=0, \\
M_{y}+\sum x_{i}\left(N_{i}-\Phi_{i}\right)=0, M_{z}+\sum x_{i} Y_{i}-y_{i} X_{i}=0 .
\end{gathered}
$$

Тут через $R_{x}, R_{y}, R_{z}, M_{x}, M_{y}, M_{z}$ - позначені відповідні проекції наосі $X, Y, Z$ векторів $R$ и $M_{O}$, а через $X_{i}, Y_{i}$ - проекції сил $F_{i}$ на осі $x, y$.

Перегрупуємо ці групи наступним чином:

$R_{z}+\sum\left(N_{i}-\Phi_{i}\right)=0 M_{x}+\sum y_{i}\left(N_{i}-\Phi_{i}\right)=0, M_{y}+\sum x_{i}\left(N_{i}-\Phi_{i}\right)=0$,

$$
R_{x}+\sum X_{i}=0, R_{y}+\sum Y_{i}=0, M_{z}+\sum x_{i} Y_{i}-y_{i} X_{i}=0
$$

Вкажемо умови, при яких існує рішення для групи (7), тобто системи, що містить $N_{i}$, що задовольняє нерівності $N_{i}>0$. Для цього введемо точку $\mathrm{K}$ на площині $X Y$ відносно якої $x, y$ - компоненти основного моменту зовнішніх сил $\Phi$ є рівними нулю. Радіус-вектор $r^{*}$ точки К буде: $r^{=}\left(x^{*}, y^{*}, 0\right)$, а $x^{*}, y^{*}$ будуть мати наступний вигляд:

$$
x^{*}=\frac{\sum x_{i} \Phi_{i}+M_{y}}{\sum \Phi_{i}-R_{z}}, y^{*}=\frac{\sum y_{i} \Phi_{i}+M_{x}}{\sum \Phi_{i}-R_{z}} .
$$

Якщо виконуються наступні умови:

$$
\sum \Phi_{i}>R_{z}, K=\left(x^{*}, y^{*}\right) \in D
$$

де $D$ - область в площині $X Y$, що $є$ випуклою оболонкою всіх точок контакту з площиною, то система (7) має рішення. Умови (10) $є$ необхідними і достатніми для того, щоб робот не відчепився від поверхні. Для того щоб робот знаходився у рівновазі необхідно виконання умов, що забезпечують відсутність відриву від поверхні і відсутність проковзування. Це означає, що при обертанні навколо довільного центру обертання $C_{O}(x, y)$ в площині контакту з поверхнею не перевищує момент сил тертя. Така умова, має наступний вигляд:

$$
\begin{gathered}
\left|M_{z}-x R_{y}+y R_{x}\right| \leqslant \sum p_{i}\left|F_{i}\right| \leqslant f \sum p_{i} N_{i}, \\
p_{i}=\sqrt{\left(x-x_{i}\right)^{2}+\left(y-y_{i}\right)^{2}}, i=1 . . n .
\end{gathered}
$$

В лівій частині нерівності (11) записані моменти зовнішніх сил відносно осі, що проходить через точку $C_{O}$ паралельно до осі $Z$, через $p_{i}$ позначено відстань від точки $C_{O}$ до $i$-тої точки контакту з 
поверхнею. При відомих значеннях $N_{i}$, необхідною і достатньою умовою відсутності проковзування буде мати наступний вигляд:

$$
X_{x, y}|Q| \leq f, Q=\frac{M_{z}-x R_{y}+y R_{x}}{\sum p_{i} N_{i}}
$$

В даній умові максимум береться по всім $x, y$. Якщо виконані умови (10) і (13), то при всіх відомих нормальних силах реакції робот буде в стані рівноваги. Але, необхідно відмітити, що система (7) являє собою сукупність з трьох рівнянь з $n$ невідомими. Тому при $n>3$ в загальному випадку система $є$ статично невизначеною.

Таким чином маємо наступний алгоритм перевірки цих умов:

1. Обраховуємо проекції вектору $R$ і моменту $M$ зовнішніх сил на oci $X, Y, Z$.

2. По формулах (2) отримуемо сили $\Phi_{i}$.

3. Обчислюемо координати точки $\mathrm{K}$ по формулах (9).

4. Перевіряємо виконання умов відсутності відриву (10). При цьому в якості множини D краще обрати випуклу оболонку всіх точок контакту, з урахуванням розмірів захватів.

5. Якщо ж хоч одна з умов (10) не виконуеться, то робот відірветься від поверхні, інакше перевіряємо умову (13), що являє собою обчислення чи оцінку максимуму функції $Q$, тобто обчислення такого числа $q$, при якому виконуеться умова $q<f[2]$.

Описаний підхід є лише одним з багатьох можливих шляхів розрахунку параметрів для утримування робота на поверхні.

\section{Способи переміщення ТP ВП}

Рух роботів вертикального переміщення може бути реалізований різноманітним чином.

Перший спосіб - дискретний кроковий. Він припускає дискретні переміщення платорори робота на заданий крок, в інтервалі між кроками відбувається фріксація однієї групи захватних пристроїв і звільнення іншої групи [3]. Перевагами даного способу є простота реалізації та надійність функціонування. Недоліки низька швидкодія і обмежені функціональні можливості.

Другий спосіб переміщення по вертикальній поверхні - безперервний кроковий. Він дозволяє робити безперервне переміщення платформи робота в шаговому режимі, при якому фіксація однієї групи захватних пристроїв і звільнення іншої групи відбувається без переривання руху платформи. Недоліками є підвищення складності алгоритму керування.

Третій спосіб - гусеничний чи колісний. Він передбачає отримання безперервної швидкості руху платформи робота за рахунок використання гусеничного чи колісного механізму [4,5]. Підвидами цього способу з гусеничним механізмом є: спосіб з використанням вбудованих в гусеничний механізм захватних пристроїв і гусеничний спосіб з незалежним використанням захватних пристроїв. В 
останньому способі гусеничний механізм служить тільки для організації поступального руху робота в межах вільного ходу приводу при зафіксованих захватних пристроях. Роботи, що використовують для руху колеса зазвичай мають систему створення вакууму між корпусом робота і поверхнею (така система має назву “ковзаючий вакуум”). Основною перевагою гусеничного способу пересування є висока прохідність і надійність переміщення. До недоліків можна віднести збільшену складність і вага конструкції. Основною перевагою колісного способу пересування є висока швидкість. Недоліком же є нижча прохідність, постійна небезпека відчеплення робота від поверхні за рахунок постійних коливань вакуумного тиску.

Четвертий спосіб переміщення - зооморфічний. При цьому способі, пересування здійснюеться за допомогою спеціальних багатоланкових структур [6]. Ці структури надають руху робо імітацію руху живих істот, в особливості комах та ящерів. Цей спосіб вимагає наявності великої кількості ступенів свободи і дуже складної системи керування. Складність конструктивної реалізації при цьому знижує надійність функціонування комплексу в цілому. Однак даний спосіб забезпечує найбільшу гнучкість при подоланні різних перешкод, при цьому в більшості роботів з даним способом переміщення рух кінцівок імітує рухи кінцівок комах чи інших живих істот, що слугували прикладом.

\section{Способи закріплення ТР ВП на поверхні}

Першочерговою проблемою проектування роботів вертикального переміщення є вибір адгезійної технології, що буде використана для утримування робота на необхідній поверхні з найменшими втратами мобільності.

Найбільш широко розповсюджений підхід закріплення роботів на поверхні, оскільки дана технологія майже немає обмежень по матеріалу поверхні і може використовуватись в різних роботах вертикального переміщення з різними способами переміщення. Керування роботом, що використовує вакуумне закріплення на поверхні є досить простим у керуванні. Зазвичай в ТР ВП використовується більше ніж один присос на “ногу” для компенсації можливих втрат тиску через нерівність поверхні чи інші непередбачені ситуації [4].

Основною проблемою використання вакуумної адгезії є обмеженість їі використання в залежності від форм поверхні. Нерівності на поверхні можуть призвести до втрати адгезії за рахунок втрати вакууму між присосом і поверхнею, що також може призвести до проковзування робота чи навіть до втрати повного зчеплення робота з поверхнею i, як наслідок, падіння робота. Також недоліком даної технології є зниження швидкості руху робота, оскільки для зчеплення з поверхнею треба створити вакуум, генерація яко- 
го потребує певного часу(в залежності від потужності генератору та розмірів і форми присосу).

3 іншого боку створення зони вакууму є окремою проблемою. Вакуум можливо створити використовуючи вакуумний насос чи генератор на базі принципу Вентурі. В обох випадках виникає питання місцезнаходження генератору вакууму. Розміщення генератору на роботі підвищує його мобільність та автономність, але це різко підвищує затрати енергії, що зменшує час автономної роботи та збільшує масу робота, що зменшує корисну вантажопідйомність. 3 іншого боку використання "наземного" генератора підвищує вантажопідйомність але знижує мобільність робота за рахунок обмежень та незручностей, що виникають за рахунок “прив'язаності” робота до “землі".

Закріплення на поверхні за рахунок магнітних сил є досить ефективним, але використання таких роботів обмежене можливістю руху лише по фреромагнітним поверхням. Зазвичай використовують електромагніти. Але також зустрічаються роботи і з постійними магнітами, що закріплені на гусені чи на колесах робота. Це дає змогу закріплятися на поверхні без зайвих витрат енергії. Також існують рішення, де використовуються магніти у формі колеса, що дає і зціплення з поверхнею і можливість руху.

Досить цікавою і прогресуючою з розвитком нанотехнологій $є$ спосіб закріплення на поверхні використовуючи “суху адгезію”. Більшість комах і ящерів можуть вільно пересуватися по стінам і стелям. Це досягається особливістю структури їніх лапок, котрі мають мікро-ворсинки, які зчіплюються з поверхнею з ефектом схожим на систему “ключ-замок”, при якому мікро-ворсинки слугують ключем для поверхні - замку. Цікавими з точки зору причеплення до поверхні є здібності гекона. Гекон з легкістю може бігати по стінам і стелі, при цьому він має змогу звисати зі стелі, “прикріпивши" себе лише одним пальцем [7]. Досліджуючи структуру пальців гекона був синтетично створений матеріал з подібними мікроволокнам, що дає змогу подібно гекону зчіплюватися з поверхнею.

Закріплення на різних поверхнях можливо і за допомогою механічних захватів. Такі захвати можуть бути у вигляді крюків, кігтів і т.д. Такий спосіб є досить обмеженим щодо типу поверхні, що потребує зміни пристрою зчеплення відносно поверхні, по якій відбуватиметься рух. Таким чином, робот, що вільно рухається по деревах буде не в змозі так само вільно рухатися, наприклад, по каменій породі. Прикладом роботу даного типу є робот RiSE (Robots in Scansorial Enviroment), що розроблений компанією Boston Dynamics [8]. Даний робот має набір “лапок” для кожного типу поверхні. Причеплення до поверхні даним способом $є$ досить ефективним 3 точки зору енергоефективності.

Одним з новітніх способів закріплення роботу на вертикальній поверхні є використання явища електроадгезії [9]. Сутність спосо- 
бу полягає у використані електростатичних сил, що виникають між поверхнею стіни чи стелі і платформою робота, для закріплення робота на поверхні.

\section{Висновки}

Технологічні роботи вертикального переміщення мають перспективи у використанні в сферах людської діяльності, де в силу різноманітних причин існуе загроза здоров'ю чи життю людини. Необхідність у мобільних роботах даного типу виникла в силу обмеженості можливостей звичайних, горизонтально-орієнтованих роботів.

Рух по вертикальній поверхні ставить нові виклики для робототехніки і механіки, так як рух даних роботів ускладнюеться, оскільки присутність гравітаційної сили призводить до виникнення нових проблем, таких як проблема закріплення роботів на стінах чи стелях і проблема руху по поверхні без відриву від неї. Наведений алгоритм розрахунку параметрів роботу для утримання на поверхні є лише одним з можливих шляхів обрахунку параметрів.

Можливі кілька варіантів способу переміщення по стінах чи стелям. Кожний спосіб переміщення відрізняється один від іншого, в першу чергу, складністю розробки як механічної структури робота, так системи керування. Кожний спосіб має свої обмеження по типу поверхні, можливій максимальній швидкості руху та ефективності закріплення робота при його русі.

Проблема закріплення ТР ВП на поверхні вирішується різними шляхами з використанням певної сили, електроадгезійної, магнітної, вакуумної чи шляхом використання механічних захватних пристроїв або використовуючи суху адгезію. Кожний спосіб має як недоліки так і переваги. Вибір способу закріплення обирається виходячи з типу і кривизни поверхні, по якій буде рухатися ТР ВП.

Таким чином, ТР ВП є частиною мобільної робототехніки, що швидко розвивається і є перспективною у використанні в багатьох сфрерах людської діяльності, особливо в умовах небезпеки для людини.

\section{Список використаних джерел}

1. Mobile Systems with Vertical Displacement Robots / V.G. Gradetskiy, M.Y. Rachkov, Y.G. Sizov, S.V. Ul'anov, F.L. Chernous'ko // Scripta Technica. - 1993. - C. 126-142.

2. Побегайлов О.А. Мобильные роботы вертикального перемещения / О.А. Побегайлов, И.В. Кравченко, С.О. Кожуховский // Ростов-на-Дону: РГСУ. - 2008. - 11 с.

3. Development of a Climbing Robot with Vacuum Attachment Cups / T.C. Apostolescu, C. Udrea, D. Duminica, G. Ionascu, L. Bogatu, 
Laureniu Adrian Cartal, Titu Maiorescu // Mechanical Engineering And New High-Tech Products Development. - 2011. - C. 258267.

4. Development of a wall-climbing robot using a tracked wheel mechanism / Hwang Kim, Dongmok Kim, Hojoon Yang, Kyouhee Lee, Kunchan Seo, Doyoung Chang, Jongwon Kim // Journal of Mechanical Science and Technolog y. - 2008. - №22. - 1490-1498.

5. Xiao J. City-Climber: A New Generation Wall-Climbing Robots / Jizhong Xiao, Ali Sadegh // Climbing and Walking Robots: towards New Applications. - 2007. - C. 383-402.

6. Design of a Bio-inspired Dynamical Vertical Climbing Robot / Jonathan E. Clark, Daniel I. Goldman , Pei-Chun Lin, Goran Lynch, Tao S. Chen, Haldun Komsuoglu, Robert J. Full, Daniel Koditschek // Proceedings of Robotics: Science and Systems. 2007. $-8 \mathrm{c}$.

7. Menon C. Gecko Inspired Surface Climbing Robots / C. Menon, M. Murphy, and M. Sitti // International Conference on Robotics and Biomimetics. - 2004. - C. 431-436.

8. Saunders A. The RiSE Climbing Robot: Body and Leg Design / A. Saunders, D.I. Goldman, R.J. Full, M. Buehler // Unmanned Systems Technolog y. - 2006. - 13 c.

9. Rong L. Wall Climbing Robot Using Electrostatic Adhesion Force Generated by Flexible Interdigital Electrodes / Rong Liu, Rui Chen, Hua Shen, Rong Zhang // International Journal of Advanced Robotic Systems. - 2013. - №10. - 9 c.

Отримано 17.03.2014 p. 